\title{
La ratio legis en la teología de Suárez y Santo Tomás. Una propuesta de comparación
}

\author{
Sebastián Contreras ${ }^{1}$ \\ INSTITUTO DE FILOSOFÍA \\ UNIVERSIDAD DE LOS ANDES
}

\section{Planteamiento. Suárez y la Ratio Legis}

Suárez, cuya filosofía de la ley se ha presentado como el punto de frontera entre la concepción medieval de la ley, «y las condiciones dominantes en la época que él escribía» ${ }^{2}$, comienza su exposición acerca de la ratio legis refiriéndose a los planteos del llamado Doctor Sanctus. Siguiendo, de esta manera, la costumbre académica de las órdenes, Suárez «explicó en sus cátedras la Summa de Tomás, y por lo tanto su famoso concepto de la ley». Y así, con la intención de mejorarlo, «y quizá también con el prurito de alcanzar originalidad, lo cotejó con otras muchas definiciones [...] recibidas de la tradición clásica» ${ }^{3}$, o debidas a otros famosos maestros universitarios como Alfonso de Castro, quien, de hecho, es una fuente directa de su pensamiento.

En este contexto, el presente trabajo intenta mostrar algunos de los puntos de continuidad y discontinuidad de los planteos tomista y suareciano acerca de la ratio legis; esto aunque pretenda más bien profundizar en la proximidad de las argumentaciones de Suárez y Santo Tomás, sobre todo en lo tocante a la importancia que ambos autores entregan a la ra-

1 Sebastián Antonio Contreras Aguirre es profesor de Derecho natural en la Universidad de los Andes (Chile). Correo: sncontre@gmail.com

2 Frederick Copleston, Historia de la filosofía. De Ockam a Suárez. De Descartes a Leibniz. De Hobbes a Hume (Barcelona, Ariel 2004), 301.

3 Francisco Puy, "Los conceptos de derecho, justicia y ley en el De Legibus de Francisco Suárez (1548-1617)», en Persona y Derecho XL (1999), 183 (por ambas citas). 
zón en el conocimiento de lo justo y de lo injusto, y a la voluntad en la determinación del derecho y la ley. Precisamente en esto, nos parece, radica su contribución, en proponer un punto de contacto entre las ideas suareciana y tomista. Esto no ha sido, por lo general, el propósito de los especialistas, quienes más bien se han encargado de marcar los puntos de quiebre entre una y otra tradición filosófico-jurídica. Y porque esto no reviste mayor interés en el debate iusfilosófico actual, sobre todo después de los trabajos de Bastit ${ }^{4}$, hemos preferido apostar por identificar la posible proximidad de uno y otro pensamiento.

Para esto, entonces, partimos del siguiente presupuesto: en la esencia de la ley se conjugan inteligencia y voluntad ${ }^{5}$. Sin embargo, escribe Santo Tomás, la ley radica más bien en la inteligencia ${ }^{6}$, porque la ley «es una palabra que procede de una peculiar prudencia y de un entendimiento que dirige al bien ${ }^{7}$. Ahora, la inteligencia, y, particularmente, la inteligencia práctica, no se conforma con juzgar lo que sea el bien o lo justo, sino que es preceptiva ${ }^{8}$. Esto se explica por el hecho de que mandar es lo propio de la razón práctica ${ }^{9}$, de manera que, y porque lo propio de la ley es mandar y prohibir, «la ley es una hechura de la razón, y por consiguiente radica en el intelecto» ${ }^{10}$.

Por este motivo, concluye Santo Tomás, el acto de la ley pertenece a la razón, porque a la razón pertenece tanto «mandar lo que debe ser hecho» ${ }^{11}$ como conocer el fin del hombre y ordenar nuestras acciones con vistas a ese fin ${ }^{12}$. Así, es la misma racionalidad de la ley, esto es, su carácter de ordenación racional al bien común ${ }^{13}$, la que la convierte

4 Michel Bastit, El nacimiento de la ley moderna. El pensamiento de la ley de Santo Tomás y Suárez (Buenos Aires, Educa 2005), 351ss.

5 Michel Bastit, «La loi», en Archives de Philosophie du droit XXXV (1990), 220.

6 Santo Tomás, Summa Theologiae, I-II, q. 90, a. 1.

7 Santo Tomás, In Ethicorum, X, lect. 14, n. 1505.

8 Santo Tomás, Summa Theologiae, II-II, q. 47, a. 8.

9 Santo Tomás, Summa Theologiae, I-II, q. 57, a. 6.

10 Domingo de Soto, De Iustitia et Iure, I, q. 1, a. 1.

11 Santo Tomás, In Sententiarum, IV, d. 33, q. 3, a. 1.

12 Juan Cruz, Fragilidad humana y ley natural. Cuestiones disputadas en el Siglo de Oro (Pamplona, Eunsa, 2009), 43.

13 Santo Tomás, Summa Theologiae, I-II, q. 90, a. 4. 
en un precepto obligatorio y vinculante ${ }^{14}$, regla y medida de los actos humanos ${ }^{15}$, y no el hecho de que emane de una autoridad competente, o de que sea efectivamente obedecida, o de que sea generada de acuerdo con un procedimiento previamente establecido ${ }^{16}$.

Pese a esto, que la ley sea formaliter un acto de la razón no significa que no sea en absoluto un acto de la voluntad. Lo que ocurre es que esa dimensión volitiva aparece como subordinada a la racional ${ }^{17}$, porque «la voluntad supone para su acto el acto del intelecto». Luego, «no pueden ser estos actos igualmente perfectos, ni igualmente a la par conseguir el último fin, sino uno antes que el otro, y uno más perfecto que el otro» ${ }^{18}$. Esto porque es el entendimiento el que ordena la operación del resto de las facultades ${ }^{19}$, incluso de la voluntad, puesto que este es el que conoce el bien, y el que muestra a la voluntad el orden necesario para alcanzarlo. Sin embargo, «la voluntad [...] puede rechazar ese orden; pero si lo rechaza pierde entonces valor o fuerza de ley, porque todo valor proviene de ese orden. $\mathrm{Y}$ es precisamente su conocimiento de ese orden lo que constituye y da forma al imperium de la razón, sobre el que decide la voluntad ${ }^{20}$.

Es en este punto donde Suárez ha dado un vuelco en la comprensión de la essentia legis. Porque mientras que Santo Tomás ha hecho de la ratio el sujeto de la acción de ordenar, Suárez, en cambio, ha dispuesto que el sujeto de la acción de ordenar no es la razón (que no puede serlo), sino que la ordinatio preceptiva de la voluntad. Dado esto, la ordinatio a la que hace referencia la definición tomista de ley, no es tan solo una

14 Francisco Bertelloni, «Sobre la dispensabilidad de la ley antigua. La posición de Domingo de Soto a la luz de la tradición medieval», en Juan Cruz (ed.), La ley natural como fundamento moral y jurídico en Domingo de Soto (Pamplona, Eunsa 2007), 111.

15 Cfr. Santo Tomás Summa Theologiae, I-II, q. 90, a. 1.

16 Raúl MAdrid, «El giro suareciano y el problema del fundamento de la ley», en Eduardo Soto Kloss (ed.), El derecho, un arte de lo justo (Santiago, Academia de Derecho Universidad Santo Tomás 1999), 54.

17 Raúl MAdrid, «El giro suareciano y el problema del fundamento de la ley», 56.

18 Juan de Santo Tomás, Cursus Theologicus, q. 5, d. 2, a. 3.

19 Cfr. Juan de Santo, In Sententiarum, IV, d. 33, q. 3, a. 1.

20 RAúl MADrid, «El giro suareciano y el problema del fundamento de la ley», 56. 
ordinatio rationis; es, asimismo, una ordinatio voluntatis ${ }^{21}$, una manifestación de la voluntad del legislador que no busca ser autónoma, en el sentido de la tradición positivista, sino que pretende concretar la racionalidad y justicia que supone la búsqueda del bien común. Por lo tanto, la voluntad ha de estar guiada por la razón en la determinación de lo que debe ser tomado por justo ${ }^{22}$, aun cuando el carácter obligatorio de las normas proceda de la voluntad, y no del entendimiento.

Bien, lo claro es que con la propuesta de Suárez, el intelecto ha quedado incapacitado para penetrar la realidad y dictar, a causa de ese conocimiento de la realidad, la ley o el derecho ${ }^{23}$. Así, al depender la obligatoriedad de las normas, no de la razón, sino del imperio de la voluntad, la inteligencia pierde su carácter normativo; ya no dicta el orden para alcanzar el bien, sino que se limita solo a conocerlo especulativamente ${ }^{24}$. Luego, es la voluntad la que tiene ahora esta función normativa; por eso es que el imperio pasa a convertirse en un acto de la voluntad.

En consecuencia, todas las propiedades que puedan atribuirse al entendimiento como sujeto de la ley (su carácter de regla y medida de los actos, su capacidad para iluminar y dirigir la actuación de los súbditos, y su condición de ordenador de la conducta), «cuadran mejor a la voluntad $»^{25}$. Esto porque, como afirmara San Buenaventura, «la voluntad es lo más noble y supremo de la substancia racional» ${ }^{26}$. Por esto es que Suárez, haciendo eco de las argumentaciones franciscanas y de los voluntaristas en general, ha puesto como referente normativo del bien o mal moral, no a la razón divina, a la Ley Eterna de Santo Tomás, sino que a la voluntad de Dios ${ }^{27}$, que, según escribe el Eximio, es fuente de todo $\operatorname{poder}^{28}$.

21 Francisco Bertelloni, «Acerca del lugar de la voluntas en la teoría de la ley y de la ley natural», en JuAn Cruz, (ed.), La gravitación moral de la ley según Francisco Suárez (Pamplona, Eunsa 2009), 65.

22 Cfr. Francisco Suárez, De Legibus, I, 12, 3.

23 Juan Cruz, Fragilidad humana y ley natural. Cuestiones disputadas en el Siglo de Oro, 91.

24 Raúl MAdRID, «El giro suareciano y el problema del fundamento de la ley», 63.

25 Francisco Suárez, De Legibus, I, 5, 11.

26 San Buenaventura, Opera Omnia, vol. III, 364b.

27 Francisco SuÁrez, De Legibus, I, 5, 11.

28 Francisco SuÁrez Defensio Fidei, III, 2, 16. 


\section{EL IMPERIO COMO ALIQUID VOLUNTATIS}

El problema de la ratio legis es el problema de la forma de la ley ${ }^{29}$, esto es, de la naturaleza y especificidad del acto de imperio. A este respecto, Suárez piensa que la función intimativa del imperio es algo que pertenece más a la voluntad que a la razón ${ }^{30}$. Santo Tomás, por su parte, postula que el imperio es inmediatamente un acto de la razón ${ }^{31}$, aunque presupuesto un acto de la voluntad ${ }^{32}$, por cierto. Y esto porque "el entendimiento es el primero que mueve, y en el alcanzar el objetivo es el primero que aprehende y conoce el objeto»; al contrario, «la voluntad se mueve por la aprehensión del entendimiento; luego, el entendimiento tiene la primacía sobre la voluntad en fuerza de la moción especificativa» ${ }^{33}$.

Así, observa el Aquinate, «si el entendimiento y la voluntad se consideran en sí mismos, el entendimiento es más excelente, como se desprende de la mutua comparación de sus objetos; y, en efecto, el objeto de la inteligencia es más simple y absoluto que el de la voluntad, toda vez que el objeto del entendimiento es la razón misma de bien apetecible, cuyo concepto se encuentra en el entendimiento ${ }^{34}$. Dado esto, imperare es esencialmente un acto de la razón, porque quien impera ordena a aquello a lo que impera hacer algo, «advirtiendo o intimando» ${ }^{35}$.

Por tanto, para que la voluntad tenga carácter de ley, precisa ser regulada por la razón. "Y es entonces cuando puede decirse con verdad que la voluntad del principe tiene vigor de ley. Sin esa regulación, semejante voluntad no sería ley sino más bien iniquidad ${ }^{36}$. De este modo, la voluntad no puede autodeterminarse en la identificación de lo bueno o de lo malo moral. Necesita estar guiada por el entendimiento. Y es más, una voluntad que no siga la dirección de la razón es la causa

29 Cfr. José Salvador Guandique, «Noción de ley. Doctrina de Francisco Suárez», en VV. AA., Actas del primer congreso nacional de filosofía (Buenos Aires, Universidad Nacional de Córdoba, 1949), 1294.

Francisco SuÁrez, De Legibus, I, 5, 14.

SAnto Tomás, Quaestiones Quodlibetales, 9, 5, 2.

Santo Tomás, Summa Theologiae, I-II, q. 17, a. 1.

33 Juan de Santo Tomás, Philosophia Naturalis, IV, q. 12, a. 5.

34 Santo Tomás, Summa Theologiae, I, q. 82, a. 3.

35 Santo Tomás, Summa Theologiae, I-II, q. 17, a. 1.

36 SAnto Tomás Summa Theologiae, I-II, q. 90, a. 1. 
directa del pecado ${ }^{37}$, piensa el Santo Doctor. De ahí que se le haya caracterizado como una potencia ciega ${ }^{38}$ : en su obrar, debe seguir el juicio práctico de la razón.

Sin embargo, escribe Santo Tomás, «relativa y comparativamente, la voluntad es a veces más excelente que la inteligencia» ${ }^{39}$, por cuanto que es la primera "que mueve en el orden de la eficiencia y de aplicar las demás potencias en cuanto al ejercicio; luego, en ese orden supera al entendimiento, que mueve solo objetivamente» ${ }^{40}$.

En estas ideas vemos ya un punto de contacto entre las argumentaciones de Suárez y Santo Tomás. Esto porque el imperio de la voluntad ha de estar sujeto al conocimiento de la razón práctica, que conoce e identifica el bien que ha de seguirse y el mal que ha de evitarse ${ }^{41}$. Entonces, y pese a que la volición es de suyo preceptiva, tal volición sigue las indicaciones de la inteligencia, por cuyo conocimiento se muestra a la voluntad lo bueno y lo malo moral.

Así, no puede decirse que en la ratio legis sea esencial tan solo el acto de la voluntad. También el conocimiento de la razón práctica juega un papel fundamental en la determinación de las normas. Porque si bien «la voluntad hace bueno al hombre dispositivamente en la vida temporal, porque es el principio del movimiento, y por lo tanto la bondad moral se realiza en la voluntad; sin embargo, eso lo tiene en cuanto se conforma con su norma, que es la recta razón $»^{42}$. De este modo, tanto el acto de la razón como el acto de la voluntad son igualmente indispensables, "y constituyen en síntesis inseparable la sustancia de toda ley»; esto sin perjuicio de que «lo que inmediatamente eleva la ley a la categoría de tal es el momento de voluntad en quien la emite» ${ }^{43}$.

Se muestra, de esta manera, la superioridad que Suárez entrega a la voluntad con respecto a la inteligencia en su filosofía de la ley, y en su

\footnotetext{
37 Santo Tomás Summa Theologiae, I-II, q. 75, a. 1.

38 Domingo de Soto, De Iustitia et Iure, I, q. 1, a. 1.

39 Santo Tomás, Summa Theologiae, I, q. 82, a. 3.

40 Juan de Santo Tomás, Philosophia Naturalis, IV, q. 12, a. 5.

41 Cfr. Santo Tomás, Summa Theologiae, I-II, q. 94, a. 2.

42 Francisco Suárez, De Anima, III, 9, 8.

43 Luis Recasens, La filosofía del derecho de Francisco Suárez (Madrid, Librería General de Victoriano Suárez 1927), 86 (por ambas citas)
} 
metafísica, por lo demás. Esto se prueba, por ejemplo, por el hecho de que el acto de amor, que es acto de la voluntad, «es más perfecto que el conocimiento natural del intelecto [...] que es imperfecto y obscuro" ${ }^{44}$. Luego, es la voluntad la que tiene preeminencia en la psicología del Eximio, toda vez que únicamente el que obra por causa de la voluntad obra libremente y puede determinarse ad opposita, de modo tal que aunque la inteligencia presente a la voluntad su objeto conocido, no la determina a esto o a aquello. Por eso, «la voluntad no se determina por nada que no sea ella misma y solo puede haber necesidad en aquello que tiene que ver con Dios mismo, no con las cosas contingentes $»^{45}$, entre las cuales se halla nuestra conducta, que es la materia de la ley.

Por lo tanto, la voluntad, escribe Suárez, es una potencia esencialmente indeterminada ${ }^{46}$, y realmente separada del intelecto ${ }^{47}$. Es más, la voluntad, así entendida, es completamente dueña de sus actos, porque estos son independientes de toda creatura. Entonces, la voluntad que es regla del obrar no queda fijada ni por su fin ni por la condición cognitiva preexistente a su propia actividad de elegir ${ }^{48}$. De ahí que Suárez haya dicho que la voluntad no puede ser determinada ni por el cielo ni por ningún otro agente creado ${ }^{49}$.

Con todo, Suárez no rechaza la intervención de la razón en la creación de la ley. Por esto es que sus argumentaciones no son las propias del voluntarismo extremo, de Ockham por ejemplo. Lo que hace es más bien posicionar a la razón en el papel que en su opinión le corresponde en el acto de imperio: bajo el dominio de la voluntad. Porque, como puede concluirse de su pensamiento, "la ley indica racionalmente las conductas correctas, pero [...] aquello por lo que la ley obliga o crea el deber de ser obedecida, más allá del simple consejo o indicación, ha de consistir en un acto de imperio, esto es, de la voluntad de quien tiene poder para imponer su voluntad».

44 Francisco Suárez De Anima, XII, 3, 6.

45 Francisco Bertelloni, «Sobre la dispensabilidad de la ley antigua. La posición de Domingo de Soto a la luz de la tradición medieval», 123.

46 Francisco Suárez, De Anima, V, 2, 1.

47 Francisco Suárez, De Anima, V, 4, 2.

48 Giannina Burlando, "Configuración psicológica de la libertad humana en F. Suárez», en Teología y Vida, XL (1999), 41.

49 Francisco Suárez, De Anima, II, 3, 18. 
En este sentido, para que lo bueno pase a ser debido, y lo malo pase a ser prohibido, "es necesario el acto de una voluntad superior y cualificada que lo ordene como tal $\aleph^{50}$. Sin embargo, y en esto es posible identificar este punto de contacto entre los planteos de Suárez y Santo Tomás del que hemos venido hablando, «la ley requiere de dos cosas: moción y dirección, bondad, por así decirlo, y verdad, esto es, juicio recto acerca de lo que debe ser hecho, y voluntad eficaz para mover a la acción ${ }^{51}, y$ esto aunque dicho juicio recto acerca de lo que debe ser hecho se vuelva inmediata y realmente ley a partir del acto de la voluntad de aquel que la establece ${ }^{52}$.

\section{SuÁrez y su concepto de ley}

Según se ha dicho, para Suárez la ley es algo que formaliter pertenece a la voluntad ${ }^{53}$. Porque, observa el Eximio, la ley no es otra cosa que «el imperio externo y el signo manifestativo de la voluntad del que manda ${ }^{54}$, esto es, "del depositario legítimo del poder público»" ${ }^{55}$. De manera que, como ha escrito Castro, el imperium legis no consiste sino en «la recta voluntad de quien representa al pueblo, promulgada de palabra o por escrito, y con intención de obligar a los súbditos a obedecerla ${ }^{56}$. Dado esto, Suárez, quien define la ley como «un precepto común, justo y estable, suficientemente promulgado» ${ }^{57}$, pone el énfasis no ya en la racionalidad del imperio, sino en su carácter de "intimatio de la voluntad»" precisamente porque, en cuanto a su esencia, la ley "consiste en la voluntad misma $"{ }^{59}$. Por esto es que en lo relativo a la moralidad de los

50 Francisco Carpintero, La ley natural. Historia de un concepto controvertido (Madrid, Encuentro 2008), 200-201 (por ambas citas).

51 Francisco Suárez, De Legibus, I, 5, 20.

52 Gonçalo Pistacchini, "Introdução», en Francisco Suárez, De Legibus. Livro I. Da lei em geral (Lisboa, Tribuna 2004), 121.

53 Francisco Suárez De Legibus, I, 5, 13.

54 Francisco Suárez De Legibus, I, 5, 25.

55 Zeferino GonzÁlez, Filosofía elemental. Moral. Nomología (Madrid, Imprenta de Policarpo López 1876), 456.

56 Alfonso de Castro, De Potestate Legis Poenalis, I, 1.

57 Francisco SuÁrez, De Legibus, I, 12, 5.

58 Francisco SuÁrez, De Legibus, II, 2, 8.

59 Francisco SuÁrez, De Legibus, II, 1, 6. 
actos humanos, "su virtud o maldad depende [inmediatamente] de su conformidad con alguna ley, y no de su conformidad o disconformidad con el juicio de la razón» ${ }^{60}$.

Según esto, caracteriza a las leyes el estar siempre referidas a relaciones entre desiguales, es decir, entre uno que es superior y unos que son inferiores. "Esa relación se establece y existe con el objetivo de que el súbdito sea gobernado y dirigido en su conducta. De ahí que [...] la ley no sea solo un consilium indicativo que puede tener lugar entre iguales, sino, sobre todo, un precepto dado por un superior a un súbdito acerca de algo que este debe hacer o debe dejar de hacer ${ }^{61}$. Porque el consilium, a diferencia de la lex, es meramente indicativo, nunca preceptivo ${ }^{62}$.

En este sentido, el centro de la propuesta de Suárez radica en haber puesto la especificidad de las leyes en su eficiencia para inducir a obrar de tal o cual forma "por medio de un vínculo moral creado por la voluntad del legislador y aceptado por la voluntad del súbdito» ${ }^{63}$. Esto solo puede ser logrado por la voluntad del superior, porque «mover y aplicar al súbdito a la ejecución de la acción" pertenece a la voluntad, "ya que el entendimiento más bien mueve en cuanto a la especificación, y por eso más bien que mover se dice que dirige" ${ }^{64}$. Se sigue de esto que la fuerza de obligar está, no en la razón, sino que en la voluntad, "ya que el entendimiento lo único que puede es mostrar la necesidad que hay en el objeto mismo, y si no la hay en el objeto, el entendimiento no puede dársela» ${ }^{65}$.

Entonces, este contenido racional de la ley es únicamente indicativo de lo justo (un simple indicio), porque, observa Suárez, «ese juicio del entendimiento aún no tiene razón de ley o de prohibición, sino que es solamente un conocimiento de lo bueno y de lo malo" ${ }^{66}$. Por eso no induce a la obligación, sino que solamente muestra la obligación que la ley

\footnotetext{
60 Francisco Suárez De Legibus, II, 5, 2.

61 Francisco Bertelloni, «Acerca del lugar de la voluntas en la teoría de la ley y de la ley natural», 62.

62 Francisco Suárez, De Legibus, I, 12, 4.

63 Raúl MAdrid, "El giro suareciano y el problema del fundamento de la ley», 59.

64 Francisco SuÁrez, De Legibus, I, 5, 15.

65 Francisco SuÁrez, De Legibus, I, 5, 15.

66 Francisco SuÁrez, De Legibus, II, 6, 6.
} 
supone ${ }^{67}$. Esto se debe, piensa el Eximio, a que el juicio de la inteligencia que define un objeto como bueno o malo no es el acto de un superior, que es lo que representa el quid de la ley, «sino que puede serlo de un igual o de un inferior, y por ello carece de toda fuerza obligante» ${ }^{68}$. De suerte que solo la voluntad del superior «tiene poder para mover eficazmente la voluntad de los súbditos, por lo que la ley es ante todo una intimatio voluntatiss ${ }^{69}$.

Por consiguiente, no existe ley alguna sino en tanto que dicho acto de conocimiento es revestido de un carácter vinculante por la voluntad del superior, que ordena como obligatorio aquello que ha sido simplemente aconsejado por la aprehensión intelectual como conforme con el orden de la voluntad divina. Prueba de esto son las ideas de Suárez acerca de la Ley Eterna. Esto porque los actos del entendimiento divino deben ir tras el decreto de la voluntad divina. Luego, «ese decreto es como el alma y la virtud de esta ley, de la cual procede eficazmente toda su fuerza de obligar o inclinar; sin embargo, supuesto ese decreto, puede concebirse en la mente de Dios el conocimiento subsiguiente de ese decreto y que, por razón de él, ya el entendimiento divino juzga de una manera determinada el plan que se va a observar en el gobierno de las cosas ${ }^{70}$. Y en este sentido, la Ley Eterna no consiste más que en «un decreto libre de la voluntad divina que establece el orden que ha de observarse, o bien en general, por las distintas partes del universo y para su bien común; o bien [...] específicamente, por las creaturas intelectuales en sus actos libres» ${ }^{71}$.

\section{LEY POSITIVA Y DETERMINATIO: LA OBRA DE UNA VOLUNTAD RAZONADA}

Tal como hemos intentado mostrar, la tesis de Suárez acerca de la naturaleza de las leyes consiste en la afirmación de una voluntad razonada, esto es, de una voluntad que sigue las indicaciones de la recta razón en la determinación de lo bueno o lo malo moral. Una idea como esta no puede ser tildada de voluntarista, no sin algunas matizaciones. Y esto porque dicho planteamiento, a pesar de entregarle una preeminencia a la

\footnotetext{
Francisco Suárez, De Legibus, II, 6, 6.

Francisco Suárez, De Legibus, II, 6, 6.

69 Francisco Carpintero, La ley natural. Historia de un concepto controvertido, 210.

70 Francisco SuÁrez, De Legibus, II, 3, 9.

71 Francisco Suárez, De Legibus, II, 3, 6.
} 
voluntad en lo que respecta a la pregunta por la ratio legis, no ha hecho más que reconocer el papel fundamental de la razón en el acto creativo de las normas: el imperio, como acto de la voluntad, sigue a un consejo de la inteligencia sobre la justicia e injusticia de las cosas.

Un ejemplo de esto lo vemos cuando Suárez declara que «la ley se deriva de la intrínseca naturaleza de la cosa, y no de la voluntad humana $»^{72}$. Esto pone de manifiesto que antes que el libre arbitrio de la autoridad competente, lo que define a una ley como tal es su racionalidad, o su conformidad con el orden de la justicia, en cuanto que únicamente la razón puede captar la naturaleza de las cosas ${ }^{73}$. Por este motivo, vemos en Suárez, no tanto al culpable del quiebre con la tradición medieval de la ley, sino al escolástico que ha intentado reposicionar los planteamientos de Santo Tomás en un contexto nuevo, con problemas nuevos y preocupaciones también nuevas. Luego, y como lo hemos dejado ver a lo largo de este trabajo, más que de las discontinuidades o del voluntarismo del Eximio, lo que nos ha interesado es mostrar su proximidad con la postura del Angélico, así como los posibles puntos de contacto entre una y otra filosofía de la ley.

Dado esto, y como ya ha quedado dicho, precisamente en el punto en donde los autores discuten el quiebre de Suárez con Santo Tomás, hemos visto el posible punto de tangencia entre una y otra tradición: en el papel de la razón como indicativa de lo bueno y justo. Ahora bien, Suárez pone en la voluntad la causa de la normatividad de las leyes. Esto porque solo aquello que la voluntad del príncipe ha dispuesto como tal puede ser tomado por ley ${ }^{74}$. Así, no es en la razón donde el Eximio ha puesto la capacidad para definir una cierta conducta como justa o injusta; dicha tarea ha sido entregada a la voluntad, porque, y en esto incluso Santo Tomás estaría de acuerdo, respecto de ciertas materias el juicio de la razón no es suficiente para la determinación de lo justo.

Estas materias, respecto de las cuales la pura razón no alcanza para la determinación de lo bueno y justo, son las llamadas cosas indiferentes, esto es, aquellas materias que no están definidas como buenas o malas, y

72 Francisco Suárez, De Legibus, II, 17, 9.

73 Cfr. Juan Cruz, «La costumbre como fundamento del derecho de gentes», en Juan Cruz (ed.), La gravitación moral de la ley según Francisco Suárez (Pamplona, Eunsa 2009), 28.

74 Cfr. Santo Tomás, Summa Theologiae, I-II, q. 90, a. 1. 
que pueden ser o no especificadas por la autoridad ${ }^{75}$ (y que pueden serlo de una manera o de otra). Según esto, existiendo un ámbito de la realidad social que sea indiferente, puede la voluntad del legislador, por ejemplo, convertir en lícito lo que sin la intervención de la autoridad política no estaría sino en contra de la recta razón, aunque no como si el derecho humano pudiera prejuzgar en contra de la voluntad divina, sino porque el legislador puede poner una circunstancia en virtud de la cual deje de ser de derecho natural o divino lo que lo sería si no existiera esa circunstancia. Un ejemplo de esto lo vemos a propósito del derecho de prescripción, que, como ha escrito Suárez, ha sido introducido por la voluntad de los hombres $^{76}$. Esto porque, observa Molina, al que posee de buena fe algo ajeno, pasado todo el tiempo para prescribir, y habiendo cumplido las determinationes de la autoridad, aun cuando la recta razón ordena la restitución de lo ajeno, «le es lícito el retenerlo a pesar de que se entere que es de otro» ${ }^{77}$.

Ahora, independientemente de cuál sea el caso, lo que importa realmente en cuanto a estas determinaciones de la libre voluntad del legislador, es que una vez que han sido establecidas como derecho vigente, aquello sobre lo que decide la autoridad deja de ser indiferente, porque entonces "observar esto es justo, y desecharlo es injusto» ${ }^{78}$. "Por esto dice el Filósofo [...] que lo justo legal es lo que, en principio, nada exige que sea asi o de otro modo; mas una vez establecido, si debe ser de un modo y no de otro». Sin perjuicio de ello, si algo connota una oposición efectiva con la ley divina o natural, "no puede hacerse justo por la voluntad de los hombres, como si se estableciera que es lícito robar o adulterar. Y por eso exclama Isaías: ¡Ay de aquellos que redactan leyes inicuas. ${ }^{79}$.

Por tanto, tales determinationes autoritativas respecto de aquello que es indiferente no las especifica la razón, sino que la voluntad de aquel

75 Rafael Fernández Concha, Filosofía del derecho o derecho natural (Madrid, Tipografía Católica 1887), 166.

76 Cfr. Francisco Suárez, De Legibus, II, 17, 3.

77 Luis de Molina, De Iustitia et Iure, I, disp. 4, 9.

78 Santo Tomás, In Ethicorum, V, lect. 12, n. 1020.

79 Santo Tomás, Summa Theologiae, II-II, q. 57, a. 2. Según esto, observa Santo Tomás que «antes que se instituyeran las leyes, en nada difería hacer esto o aquello. Pero una vez instituidas [...] las cosas cambiaron, porque desde entonces lo justo va a consistir en observarlas y lo injusto en pasarlas por alto, como en cierta ciudad fue instituido que el cautivo sea redimido pagando un cierto precio, y que se sacrificara una cabra pero no dos ovejas». 
que es superior. «Pero cuando los discípulos de Santo Tomás hablan de la voluntad humana o del libre albedrío del hombre, no desligan la voluntad de la recta razón, es una voluntad recta. Lo cual significa que en esta materia es grande el margen de decisión de la voluntad del gobernante, pero en modo alguno es incurrir en el voluntarismo pues son numerosos los límites de la potestad legislativa de la autoridad pública» ${ }^{80}$.

Por razón de lo expuesto, critica Suárez la posición de aquellos que han planteado que únicamente pueden ser materia de las leyes humanas los actos que han sido mandados o prohibidos por la ley natural o divina. Tal planteamiento es abiertamente erróneo, escribe, porque "consta por la práctica que esas leyes mandan muchas cosas que antes no eran necesarias" ${ }^{81}$. Y es más, «aún las cosas que están mandadas de una manera general por la ley divina o natural, pueden determinarse de distintas maneras». Esto se ve claramente en la reglamentación de los delitos, porque la ley humana con prudente libertad determina la clase de pena correspondiente para un delito particular ${ }^{82}$. De ahí que, concluye el Eximio, «dicen los teólogos que algunas cosas son malas porque están prohibidas por la ley [y la voluntad] humana, ya que de suyo no eran malas; luego anteriormente a la ley eran indiferentes, pues si hubiesen sido buenas, la ley no hubiese podido hacerlas malas» ${ }^{83}$.

En consecuencia, y ante lo indiferente, no es la razón la que puede especificar lo que sea conveniente para cada caso; porque el juicio de la inteligencia puede referirse a alternativas igualmente válidas pero contrapuestas. Luego, ante lo que es indiferente, la razón no es capaz de precisar un enunciado normativo que pueda dar cuenta de aquello que para este caso concreto ha de ser tomado como conveniente o inconveniente. De manera que solo la voluntad puede establecer formalmente este juicio de conveniencia o inconveniencia de lo indeterminado por la ley divina ${ }^{84}$. Así, dada esta doctrina de la determinatio, siendo la voluntad

80 Juan Castillo, El mundo jurídico en Fray Luis de León (Universidad de Burgos 2000), 186.

81 Francisco Suárez, De Legibus, III, 13, 13.

82 Francisco Suárez, De Legibus, III, 15, 14.

83 Francisco Suárez, De Legibus, III, 15, 16.

84 Cfr. James Bernard Murphy, "The significance of customary law in the philosophy of Francisco Suárez», ponencia presentada en la Conferencia anual de filosofía cristiana, 2006 
esencialmente activa y dueña de sus actos, «puede encaminar su esfuerzo hacia la dirección que más se le antoje, incluso hacia las direcciones más opuestas» ${ }^{85}$. Esto porque, observa Suárez, la voluntad «no está determinada solamente a una cosa, sino que de suyo es indiferente a obrar esto o aquello, y a obrar o no obrar, una vez puestos todos los requisitos para la operación ${ }^{86}$.

Ocurre, de este modo, que respecto de las materias indiferentes, «la voluntad produce una necesidad que no había en el objeto: así, por ejemplo, en materia de justicia, hace que la cosa valga tanto o cuanto, y en materia de otras virtudes, que en este caso particular sea obligatorio hacer una cosa que en otras circunstancias de suyo no lo sería ${ }^{87}$. Ahora, $\mathrm{y}$ en esto nos parece que se halla la vinculación con el proyecto de Santo Tomás, «si el acto es por su naturaleza intrínsecamente malo», esto es, de suyo contrario a la recta razón, «la ley humana [...] nunca puede mandarlo, porque no es separable de él malicia ${ }^{88}$ que lo constituye.

\section{ConClusiones. SUÁrez y SU VOlUNTARISMO MODERADO}

El voluntarismo de Suárez no es el voluntarismo de Ockham, o el de alguno de los Nominales. Si así lo fuera, no cabría siquiera hablar de una posible proximidad entre su pensamiento y los planteamientos de Santo Tomás. El voluntarismo de Suárez es más bien un voluntarismo moderado, un voluntarismo que revalora el papel de la razón, un voluntarismo donde el apetito racional sigue al juicio de la inteligencia práctica en la determinación del derecho y la ley. Y es que ambos, intelecto y voluntad, son necesarios a la ley, porque «la ley se compone y se constituye por los actos de ambas potencias» ${ }^{89}$. Y de este modo, no habría ley «sin una intención a ella inherente de obligar, y sin un ordenamiento al bien común de la comunidad», de modo que, junto con esta ordenación racional al

\footnotetext{
85 Antonio López, "Causalidad y libertad en Suárez y en la polémica De auxiliis», en Logos. Anales del seminario de metafísica, III (2001), 93.

86 Francisco Suárez, Disputationes Metaphysicae, XIX, 2, 11.

87 Francisco SuÁrez, De Legibus, I, 5, 15.

88 Francisco Suárez, De Legibus, III, 15, 18.

89 Francisco Suárez, De Legibus, I, 5, 11.
} 
bien común, «hay además un acto voluntario [...] en el legislador $»^{90}$, el que decide libremente la promulgación efectiva de la ley.

Un ejemplo de esto lo vemos a propósito del tratamiento suareciano de la ley natural. Así, en opinión del Eximio, «aunque la obligación de la ley natural sea propiamente preceptiva por cuanto se deriva de la voluntad de Dios, dicha voluntad supone un juicio acerca de la maldad o la mentira»" ${ }^{11}$ cuestión que corresponde a la razón en su uso práctico. Así, Suárez, que rechaza el voluntarismo extremo por desembocar en una verdadera negación de la ley natural, es, por ello mismo, partidario de que esta sea considerada sustancialmente «un acto de la voluntad, solo que con un fundamento in re» ${ }^{92}$. Por esto es que afirma que "en el acto humano hay alguna bondad o malicia en virtud del objeto absolutamente considerado, en cuanto que está conforme o no con la recta razón, puesto que según ella se puede llamar malo o [...] culpable» ${ }^{93}$.

Pese a esto, «no basta que el legislador juzgue que algo debe hacerse, ni es suficiente que quiera hacerlo. Es indispensable que lo ordene de manera eficaz». Por tanto, «existe la ley, cuando el legislador ordena o impone eficazmente lo que ha sido aprobado por su razón práctica o lo que ha sido aceptado por su voluntad recta» ${ }^{4}$. En este sentido, «se entiende mejor y más fácilmente se defiende que la ley [...] es en el mismo legislador un acto de la voluntad justa y recta, por el cual quiere obligar al inferior a esto o aquello» ${ }^{95}$. Y, por tanto, como se trata del acto de una voluntad recta, por ello mismo presupone un acto del entendimiento acerca de lo que se ha de tener por bueno o malo moralmente ${ }^{96}$.

90 Francisco Leocata, «Libertad y ley», en Juan Cruz (ed.), La gravitación moral de la ley según Francisco Suárez (Pamplona, Eunsa 2009), 46 (por ambas citas).

91 Francisco Suárez, De Legibus, II, 6, 13.

92 Mauricio Beuchot, Derechos humanos, iuspositivismo y iusnaturalismo (México DF, UNAM 1995), 115.

93 Francisco Suárez, De Legibus, II, 6, 11.

94 Luciano Pereña, «Introducción», en Fray Luis de León, De Legibus o Tratado de las leyes (Madrid, CSIC 1963), XLIX (por ambas citas).

95 Francisco SuÁrez, De Legibus, I, 5, 13.

96 Cfr. Javier Hervada, Historia de la ciencia del derecho natural (Pamplona, Eunsa 1996), 237. 
Entonces, la ley, concluye Suárez, «no está limitada a significar tan solo un acto del intelecto o de la voluntad ${ }^{97}$, sino que de ambas potencias, y de esta manera «la ley natural prohíbe aquellas cosas que en sí son malas; pero esta ley es verdadera ley divina y verdadera prohibición; luego, es necesario que añada alguna obligación de evitar el mal que es de suyo tal» ${ }^{98}$. Esto se logra por medio de la voluntad divina ${ }^{99}$, que, no obstante ser la causa inmediata de la obligatoriedad de la ley de la naturaleza, «supone un juicio previo de la malicia $v . g r$. de la mentira ${ }^{100}$. Luego, también para Suárez, como lo había sido para Santo Tomás, lo bueno y lo malo se dice, en cierta manera, por comparación al orden de la razón ${ }^{101}$.

Ahora bien, y como ya ha sido dicho, lo que convierte al juicio de la razón práctica en ley es el imperio de la voluntad. Y esto porque el acto de la voluntad es más perfecto que el acto del entendimiento, piensa Suárez. Así, cuando comparamos uno y otro, resulta que el acto más perfecto de la voluntad es amar a Dios, y aunque el acto más perfecto del intelecto sea conocer a Dios, es mejor amarle que conocerle, al menos en la vida presente ${ }^{102}$.

En definitiva, el pensamiento de Suárez acerca de la essentia legis oscila entre ratio y voluntas. Porque cuando enfatiza el momento voluntarista, "procura al mismo tiempo salvar el momento intelectual, y porque cuando destaca el momento intelectual, procura al mismo tiempo salvar y conservar el momento voluntario». Se trata, por tanto, «de un gran esfuerzo conceptual y sistemático por lograr una concordantia discordantium» ${ }^{103}$, un esfuerzo por la novedad de su proyecto filosófico, un proyecto que se mueve entre el respeto por la auctoritas del Angélico, y la necesidad de una renovación de la filosofía de la ley en razón de las nuevas necesidades y preocupaciones de su tiempo.

97 Francisco Suárez, De Legibus, I, 12, 3.

98 Francisco SuÁrez, De Legibus, II, 6, 8.

99 Francisco Suárez De Legibus, II, 6, 5.

100 Francisco Suárez, De Legibus, II, 6, 8.

101 Francisco SuÁrez, De Bonitate et Malitia Humanorum Actuum, 9, 3, 10.

102 Cfr. Juan Fernando Sellés, Conocer y amar. Estudio de los objetos y operaciones del entendimiento y de la voluntad según Tomás de Aquino (Pamplona, Eunsa 2000), 231.

103 Francisco Bertelloni, «Acerca del lugar de la voluntas en la teoría de la ley y de la ley natural», 72 (por ambas citas). 
Resumen: El presente trabajo intenta profundizar en las nociones de ley de dos de los más importantes teólogos escolásticos: Tomás de Aquino y Francisco Suárez. Sabemos que el Eximio pretende dar sentido e inteligencia a las palabras del Aquinatense. Usualmente se ha marcado el voluntarismo y distancia que toma Suárez con respecto a la teología del Maestro Angélico, motivo por el cual hemos querido bosquejar una posible continuidad entre ambos doctores de la teología escolástica: todo a partir del análisis del concepto de imperium.

Palabras clave: Ratio legis, ley en general, imperium, determinación.

Abstract: This paper tries deeper into the notions of law of two of the most important scholastics: Aquinas and Suarez. We know that Suarez tries give sense and intelligence at the Aquinas' words. Usually we mark the voluntarism and the distance that Suarez takes over the Aquinas' theology; for this we wanted outline a possible continuity between the two doctors of scholastic theology: everything from the analysis of the concept of imperium.

Keywords: Ratio legis, law in general, imperium, determination. 